\title{
SOIL FERTILITY PROBLEMS IN TARANAKI
}

\author{
C. DURING, Principal Scientific Officer, Department of \\ Agriculture, Wellington
}

In this talk I intend to deal only with some of the major soils derived from volcanic ash, not with sand country or the hill soils derived from mudstone and sandstone. These volcanic soils of Taranaki suffer from two major deficiencies, phosphorus and potassium.

\section{Paddocks not Heavily Topdressed in the Past}

$\mathrm{Mr}$ A. C. Burgess has done much work in comparing rates of superphosphate or serpentine-superphosphate on pastures. On sites moderately heavily topdressed or little topdressed in the past he obtained the following results:

(1) On newly-sown pastures after a crop he could usually observe increasing growth response from $3 \mathrm{cwt}$ up to as much as 13 cwt of serpentine-superphosphate per acre, which was the highest rate tried. These responses could clearly be seen in the newly-sown ryegrass in the first autumn and winter.

(2) On undisturbed pastures 5 to $6 \mathrm{cwt}$ per acre of superphosphate were commonly better than 3 to $4 \mathrm{cwt}$. Higher rates of application were not always tried on these pastures.

Dr W. M. H. Saunders, D.S.I.R., will tell you about the result of his work with rates of phosphatic fertilisers on an old untopdressed pasture. His results were similar to those obtained by Burgess.

\section{Paddocks Heavily Topdressed for Several Years}

Heavy consistent topdressing with phosphatic fertilisers increases the phosphorus in the soil which is available to plants. The magnitude, however, of this residual -effect and the period of time over which it is effective, varies with soil type. Most soils in Taranaki have the reputation of being bottomless pits into which applied phosphate disappears without leaving useful residues. This is fortunately an exaggeration.

The most precise work on the residual effect of applied phosphatic fertilisers has been carried out by Dr Saunders, but some work was done by Mr Burgess. They found that the residual effect of phosphatic fertilisers depended on the season of year in which 
it was measured, but generally it was low. Nevertheless the effect of regular heavy phosphatic topdressing on the subsequent level of available phosphorus was appreciable; and there is no doubt that it is of great practical importance. A few experiments illustrate this point.

In an observational trial placed on a paddock which had received nearly 4 tons of superphosphate in the preceding 25 years only very small responses to serpentine-superphosphate could be observed. ( $P$ soil test $=6$ ). In another observational trial ( $P$ soil test $=9) 10 \mathrm{cwt}$ of serpentine-superphosphate per acre appeared to produce no better pasture vigour than $2 \mathrm{cwt}$. On the Waimate West Demonstration Farm, near Manaia, a rather precise yield measurement trial was carried out by Mr B. Smith. The phosphorus quick test was 8-10. Part of the trial was ploughed and resown, and part was left in the original pasture. The only growth response to phosphatic fertilisers was obtained in the autumn of the second year. The trial was then closed.

Hence there appears to exist in Taranaki a range of phosphorus fertility from very low to high. The position can be summarised as follows: On newly broken in land the soil supplies very little available phosphorus. Therefore a large amount has to be supplied from the bag. But this fertiliser-derived phosphorus accumulates in the topsoil, remains somewhat available to pasture, and repeated applications slowly increase the phosphate-supplying power of the soil. As this happens less needs to be supplied in the form of mineral fertilisers to obtain a high level of total available phosphorus. This is diagrammatically illustrated in Fig. 1.

Total available phosphorus at adequate level

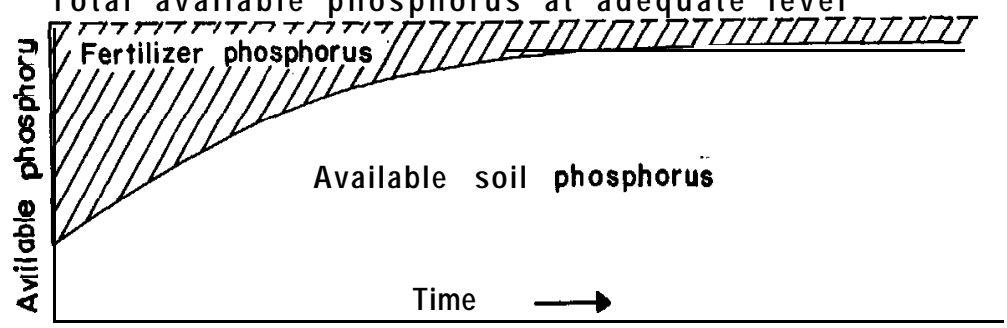

Fig. 1

\section{How Many Paddocks Have High Phosphorus Fertility?}

From the evidence which we have and which I have mentioned, it appears that the phosphorus soil quick test (Truog's method) used by the Department of Agriculture may give a fairly reliable 
indication of phosphate availability. A large number of quick tests have been carried out in Taranaki. The results of these tests as well as information on past topdressing and pasture quality are recorded on a card system. From this source of information we can obtain a very good idea of soil fertility trends provided we remember that:

Those who ask for soil tests are the more interested members of the farming community and possibly topdress more heavily than the average. For instance: Private farm improvement clubs enjoy a heavier than average density of soil sampling. The members of these clubs also obtain frequent and regular professional advice, which would result in rates of topdressing above the average.

With this in mind let us consider the following data from over 1,200 soil samples:

On a soil of coastal south Taranaki over 40 per cent of all samples taken had a relatively high phosphate soil test ( 7 and over). On a large group of soils of Central and North Taranaki the figure was 24 per cent.

\section{Potassium}

Potassium (potash) is the other important soil deficiency in Taranaki, but we have much less useful information on the needs for potassic fertilisers. Also we are less confident about the meaning of the potassium soil quick test.

There are inherent difficulties about the interpretation of experiments with rates of potassic fertilisers on pastures and the meaning of the potassium soil quick test. Nevertheless Mr Burgess and other officers of the Department of Agriculture have carried out a large number of trials with rates of muriate of potash (potassium chloride). They have shown that even on virgin soils (as soon as they are adequately dressed with phosphatic fertilisers) pasture responses to potassium are likely in many parts of Taranaki. This is in contrast to our experience in many other areas. Potassium deficiency appears to become more severe as pastures are improved with phosphate, and growth responses to rates up to 4 cwt of muriate of potash per acre are not uncommon.

Again, a wide range of potassium soil quick test levels are found. This probably indicates a fairly wide range of potassium fertility within the province. The South Taranaki soil has a higher mean potassium soil test level than the group of soils further north. 


\section{How Do Farmers React to the Changing Phosphorus Fertility?}

The information stored in our soil test records is capable of giving a fairly accurate answer. Fig. 2 gives this for the soils in

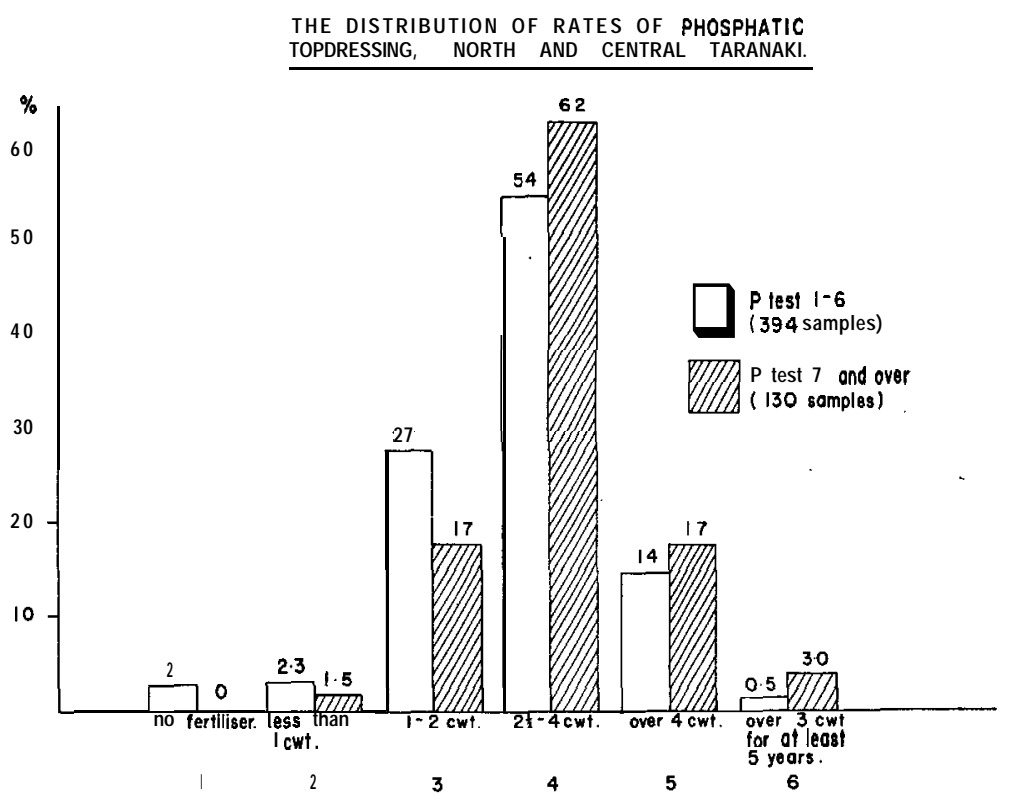

Fig. 2: Rates of super or serpentine super used on paddocks with "not high" and "high" P tests. Note: Rates referred to were applied each year for two years preceding soil testing, except in class 6 where records are known for five years or more.

North and central Taranaki. When paddocks are grouped according to "high'? and "not high" soil phosphorus quick test levels, it is seen that the paddocks with the high soil tests receive more phosphatic fertilisers than those with the lower tests. The direct effect of rate of phosphatic topdressing over a period of 2 years on the soil phosphorus quick test is known to be small. Many years of heavy topdressing, however, do change' the soil test. Therefore the association of high soil P tests with relatively heavy topdressing over the previous two years leads to the following interpretation:

1. Farmers seem to continue the habit of fairly heavy phosphatic topdressing beyond the stage of proven need.

2. More phosphatic fertiliser is applied to paddocks which need it least than to paddocks which need it most. 
dur information on the relationship of the. potassium quick test and potassic topdressing is more difficult to interpret. For this reason I do not intend to show details.

\section{The Effect of Topdressing on Pasture Quality}

Most farmers use mixtures of potassic and phosphatic fertilisers. The separate effect of each of these fertilisers on pasture quality is therefore difficult to determine without experimentation.

Table I shows the association of pasture quality with rates of phosphatic and potassic topdressing found on over 800 paddocks soil sampled in central and north Taranaki during 1955-62. It must be realised that the figures shown represent an association and not a proven cause-and-effect relationship. In view of the large number of samples, however, it is likely that cause and effect play a large part. In other words, if a higher rate of topdressing is associated with higher pasture vigour, it is likely that the increase in pasture vigour is, to a great degree, caused by the heavier rate of topdressing.

TABLE I-RATES OF PHOSPHATE AND POTASSIC TOPDRESSING AND PASTURE VIGOUR (VIGOUR RATING O-20)

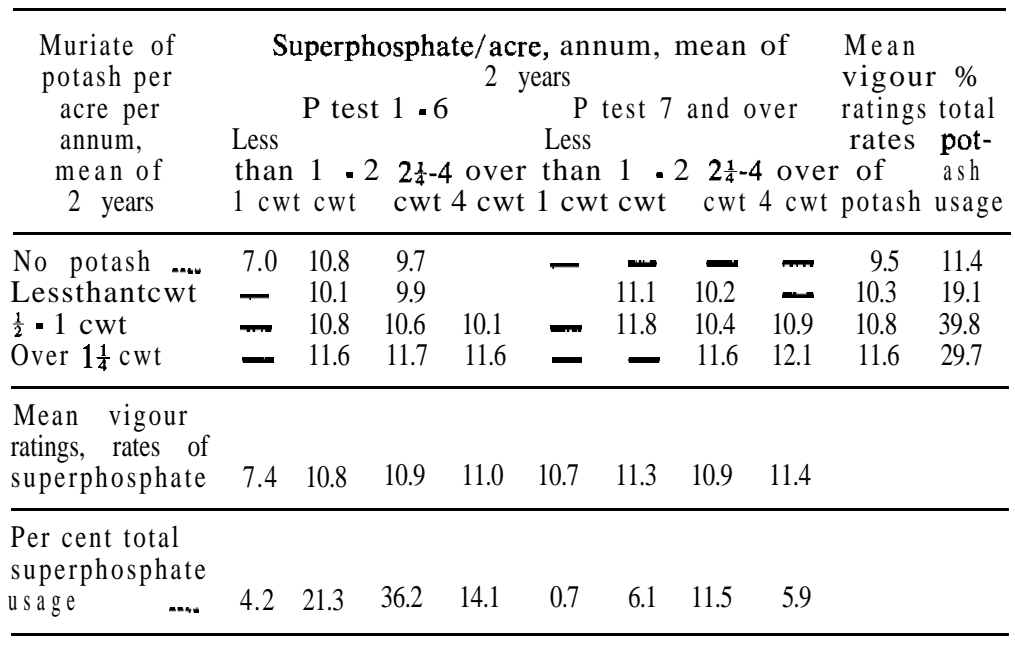

In this table the pasture vigour of topdressing combinations is shown only if represented by more than 10 samples. The omitted combinations, however, are included in the data showing the mean vigour ratings. 
This table goes some way in explaining the presence of many relatively poor pastures in Taranaki. It illustrates the following points :

1. At any one rate of application of potash (look along rows) an increase in the rate of application of super-phosphate or serpentine superphosphate is not associated with an increase in pasture vigour. A possible exception are the two paddocks with a high phosphate test which have been heavily topdressed with potash in the two years preceding the taking of soil samples.

2. In contrast, at any one rate of application of phbsphatic fertilisers (look down column) an increase in the rate of potash is associated with a clear increase in pasture vigour.

3. Thirty per cent of all paddocks sampled had not received more than nominal amounts of potash in the 2 years preceding soil sampling. Another 40 per cent had been topdressed with rates associated with rather low pasture vigour. These results, however, include soil samples taken since late 1955. It is known that since then the use of potassic fertilisers has increased greatly. Yet it is likely that it has not yet reached a desirably high level.

4. Table 1 suggests that on a majority of paddocks for every $2 \mathrm{cwt}$ of superphosphate used at least $1 \mathrm{cwt}$ of muriate of potash should be used.

\section{The Time of Application of Fertilisers}

In trials at Marton superphosphate applied in early March tends to stimulate the growth of ryegrass in late autumn and winter without necessarily stimulating the growth of white clover. In contrast muriate of potash applied at the same time has not stimulated the growth of ryegrass during this crucial time of the year. Since, in late autumn, the rate of growth of white clover is declining, potash has had no appreciable stimulating effect on this species until about mid-August. From then onwards, however, potash has greatly increased pasture yields, almost entirely because of its effect on white clover growth.

The net result was that growth responses to autumn topdressing were not the same for potassic and phosphatic fertilisers. It seemed clear that phosphates should be applied in autumn. Potassic fertilisers, however, were considered to be more effective if applied in late spring. This situation, however, may not apply everywhere. In warmer districts, and Perhaps also on more freely draining soils than those of Marton, white clover may well grow longer into autumn. This may mean that it is capable of giving a worth-while immediate response to potassic fertilisers applied in March. Obviously, the best time of applying potassic and phosphatic fertilisers in Taranaki needs investigating. 


\section{SUMMARY}

Two main soil fertility problems need further urgent study in Taranaki.

1. We have inadequate knowledge of phosphorus and potassium fertility trends on pastures regularly topdressed. It would seem particularly important to define the most economic ratios of potassic to phosphatic fertiliser to be used under different conditions. Indirect evidence suggests that more emphasis should be placed on potassic topdressing.

2. Since many farmers topdress twice yearly a study of time of application of both phosphatic and potassic fertilisers is worth while. It may show that the traditional way of applying potassic superphosphate mixtures may not always be the best.

\section{Acknowledgements}

I wish to thank Mr W. R. Dale and Mr D. Martin for compiling much of the data used in this paper, I should also like to express my appreciation to $\mathrm{Mr} \mathrm{G}$. R. Moss for constructive criticism.

\section{DISCUSSION}

Q. (Prof. Walker): You have talked solely of the phosphate content of superphosphate and not of its sulphur content. Have you any evidence to show 'that gypsum is having no effect on pasture growth?

A. Observational trials with sulphur have given no indication of a need for this element.

Q. You suggested that, as topdressing is increased the need for applied phosphate will decline. In practice as you apply more fertiliser you get more growth. As a result more is carried off in farm produce. Would you not anticipate that still more fertiliser would be needed?

A. Fertiliser will be needed to compensate for losses from the grazing area by transfer within the farm and off the farms. The quantity needed will depend on the desired level of pasture production, In my talk I have assumed equal production throughout.

On many soils very heavy initial topdressing can raise pasture production very rapidly, and once a high level of production has been achieved available evidence suggests that rates of phosphatic topdressing can be gradually reduced. On the other hand the demand for potassic fertilisers may remain high or may increase with time. I suspect that this is happening on many farms in Taranaki. Too little potassium is used in relation to the amount of phosphatic fertilisers which are and have been applied. This is not the same thing as saying that given adequate potassic topdressing, farmers are at present applying too heavy rates of phosphatid fertiliser. But it is possible that at the present inadequate average levels of potassic topdressing many farmers are applying more phosphate than the potash starved pastures can economically utilise.

Q. (C. Tebb): If pumice soil is adequately topdressed for a prolonged -period of time will a need for lime then arise?

A. This is difficult to answer. Pumice soils differ considerably. Certainly on some soils low pH may develop after years of intensive farming. 
Also some trace elements such as copper and possibly iron may be in low supply on some soil types. The need for lime therefore needs to be considered on individual soil types and in connection with the effect of liming on the availability of trace elements.

Comment. (Dr Saunders): Regarding the need for lime the volcanic ash soils are strongly buffered because of their high allophane content. Thus they need very heavy dressings of lime to change soil $\mathrm{pH}$. This may explain why there has been no response.

Q. When we used lime during the wartime fertiliser rationing period we had little or no bloat. Has Mr During considered the use of lime from this viewpoint?

A. No. The Department of Agriculture has not carried out any work on this point. Fertiliser rationing, however, had led to lower clover and grass vigour. This by itself may have a bearing on the incidence of bloat.

Q. (Dr Saunders): Would you indicate the differences needed to obtain statistical significance in your table showing the pasture.vigour ratings and their association with topdressing? I ask this having in mind the possibility of using higher rates of application than those recommended.

A. These data were not statistically analysed but from previous work it is probable that a difference of 0.3 to 0.5 would be significant.

Q. (Dr O'Connor): You presented an idealistic concept of phosphate availability increasing with time. Is this only a theoretical ideal or is it actually increasing?

A. When results of our topdressing trials with phosphatic fertilisers are correlated with the phosphorus soil quick test it appears that on the volcanic soils of Taranaki phosphorus availability seems to be much greater at higher soil test levels. On the other hand the graph shown in this paper is not intended to show a precise quantitative picture of this increase. It is only intended to put across the general idea;

Q. (Dr. O'Connor): In relation to the bloat problem, if the fertility index is based on the vigour of clovers and grasses, and having in mind the grass response to phosphate found at Marton, is the application of potash the type of thing we want? Should you not apply more phosphate to increase grass growth?

A. The grass response to phosphate probably occurs only in late autumn and winter and must be dependent on a fairly adequate supply of available nitrogen. In fact at that time it seems that on the Marton loam, on the farms considered, the available supply of nitrogen for grasses is slightly better than that of phosphorus.

In the long run, however, nitrogen fertility depends on clover vigour, and this vigour can only be assured by topdressing with potash.

One might perhaps induce relative white clover dominance for lamb fattening by using a high K/P ratio but I doubt whether one can combine high production with relative grass dominance by using a low $\mathrm{K} / \mathrm{P}$ ratio. At least this seems unlikely in Taranaki.

Q. In view of the leaching of potassium due to the high rainfall in Taranaki, would $1 \mathrm{cwt}$. of potassium chloride per acre per annum be sufficient?

A. For high production probably not.

Q. To reduce the incidence of bloat would the practice of running a few sheep ahead of the cows to remove the clover leaf do any good?

A. I cannot answer this. 